\title{
A pesquisa na formação inicial dos professores de Educação Física
}

\author{
Néri Emilio Soares Júnior* \\ Lívia Freitas Fonseca Borges***
}

\begin{abstract}
Resumo: O presente estudo tem o objetivo analisar o lugar da pesquisa no currículo de um curso de formação inicial de professores de Educação Física para a Educação Básica. Foram utilizados como instrumentos de levantamento de dados a análise documental, o questionário, a entrevista semiestruturada e o grupo focal. Foi compreendido que a pesquisa possui uma indicação de inclusão em todas as disciplinas. Os interlocutores reconheceram a existência da inclusão da pesquisa no currículo do curso de licenciatura em Educação Física da instituição. Também ressaltaram que esse processo apresenta limites e possibilidades.
\end{abstract}

Palavras-chave: Docentes. Currículo. Pesquisa. Educação física.

\section{Apresentação}

A Educação Física sofreu em sua história uma forte influência da racionalidade técnica nos currículos dos cursos de formação de professores (BORGES, 1998; MOLINANETO, 1997; TAFFAREL, 1993) o que contribuiu para a não inserção da pesquisa em seus programas de formação. Isso aconteceu porque a racionalidade técnica é modelo de formação que concebe o professor como um aplicador de conhecimento e técnicas (PÉREZ GOMES, 1992). Dessa forma, não houve uma preocupação com a inclusão efetiva da pesquisa nos currículos, uma vez que, nesta perspectiva não era função do profissional da Educação Física produzir conhecimento (BRACHT, 2003).

\footnotetext{
"Professor Substituto. Faculdade de Educação Física. Universidade de Goiás. Goiânia, GO, Brasil. E-mail: nemsoju@bol.com.br

"Professora da Faculdade de Educação. Universidade de Brasília. Brasília, DF, Brasil. E-mail: liviaborges@fe.unb.br
} 
É importante ressaltar que, além de possibilitar a produção do conhecimento científico, a pesquisa ocupa um importante lugar na Formação Inicial de professores, pois possibilita a integração entre o estudante universitário, Formação Inicial e a realidade escolar. $\mathrm{Ou}$ seja, a pesquisa, nos programas de Formação Inicial de professores, pode possibilitar o confronto entre os referenciais teóricos com a realidade do trabalho, contribuindo assim com o processo reflexão na prática pedagógica (ANDRÉ, 2006) o que contribui com uma leitura crítica da realidade (PIMENTA, 2006).

E, a partir desta problemática, o objetivo desse estudo foi analisar o lugar da pesquisa no currículo de um curso de Formação Inicial de professores de Educação Física para a Educação Básica.

A pesquisa então foi desenvolvida em torno de três eixos: Formação Inicial de professores, currículo e pesquisa. E a sua orientação metodológica foi balizada pela ideia que Gimeno Sacristán (2000, p. 34) apresenta sobre os níveis de decisão curricular. Segundo este autor, o currículo é um "[...] projeto seletivo da cultura, cultural, social, política e administrativamente condicionante, que preenche a atividade escolar e que se torna realidade dentro das condições da escola tal qual como se acha configurada". Desse modo, o currículo de uma instituição de ensino é construído em um processo complexo, no qual diferentes decisões são tomadas em diferentes instâncias e por diferentes sujeitos.

O início desse processo acontece via políticas curriculares que estabelecem uma proposta de currículo advindo das políticas públicas. Gimeno Sacristán (2000) denomina este nível curricular como currículo prescrito ou oficial, sendo que este é apresentado aos professores em forma de documentos oficiais. No caso dos cursos de formação, os professores recebem este currículo advindo de Decretos, Resoluções, Diretrizes e outros documentos. Sendo assim, as Diretrizes Curriculares Nacionais para a formação dos professores para a Educação Básica representam a prescrição curricular oriunda das Políticas Públicas que visam estabelecer princípios, fundamentos e procedimentos a ser observados na organização curricular de cada estabelecimento de ensino. 
O currículo oficial, ao chegar às instituições de ensino, sofre interferência do corpo docente e dos demais sujeitos que o vivenciam. Sendo assim, o currículo passa a ser modelado por esses sujeitos a partir da cultura profissional, primeiro sendo materializado no projeto educativo da instituição, no Projeto Político Pedagógico e nos Planos de Ensino das disciplinas que compõem a matriz curricular; e, segundo, na ação do currículo na realidade vivida por professores e alunos situada no interior da sala de aula (GIMENO SACRISTÁN, 2000).

A partir desta dinâmica curricular, é que orientamos nosso estudo, uma vez que nosso propósito foi o de investigar o objeto de estudo, a pesquisa, nessas diferentes instâncias do currículo. Esta teve como partida o currículo estabelecido nas políticas curriculares, passando pela modelagem dos professores registrada no projeto educacional do curso de licenciatura e nos planos de ensino até chegar à percepção que os docentes e discentes apresentam do currículo em ação. Assim, tivemos como objetivos específicos: a) compreender se a pesquisa é componente integrante das Diretrizes Curriculares Nacionais para formação do professor para a Educação Básica; b) analisar a concepção e a indicação de inclusão da pesquisa estabelecida no Projeto Político Pedagógico do curso investigado; c) analisar a percepção dos docentes e discentes sobre a inclusão da pesquisa em seu currículo.

A investigação foi realizada em uma instituição do Estado de Goiás, que será abordada pelo nome genérico Instituição Formadora com o intuito de se resguardar sua identidade e também daqueles que lá desenvolvem suas atividades. Foi desenvolvido um estudo de caso com a utilização dos seguintes procedimentos de levantamento de dados: a análise documental, o questionário, a entrevista semiestruturada e o grupo focal. Os interlocutores da pesquisa foram docentes e discentes da Instituição Formadora.

Os documentos analisados foram os Referenciais para Formação de professores, as Diretrizes Curriculares Nacionais para Formação dos Professores para a Educação Básica composta pelo: a) Parecer $\mathrm{CNE} / \mathrm{CP} \mathrm{n}^{\circ}$ 09, de 8 de maio de 2001 que fundamentou 
as Diretrizes Curriculares Nacionais para a Formação Inicial de professores da Educação Básica em nível superior que trata da formação de professores para a Educação Básica; b) Resolução $\mathrm{CNE} / \mathrm{CP} \mathrm{n}^{\circ}$ 01, de 18 de fevereiro de 2002, que instituiu as Diretrizes Curriculares Nacionais para a formação de professores da Educação Básica, em nível superior, curso de licenciatura, graduação plena. Além da Resolução CNE/CP n ${ }^{\circ}$ 02, de 19 de fevereiro de 2002, que instituiu a duração e a carga horária dos cursos de licenciatura, de graduação plena, de formação de professores da Educação Básica em nível superior. Também foram analisados o Projeto Político Pedagógico do curso de Licenciatura em Educação Física da Instituição Formadora e os programas de ensino das disciplinas ministradas pelos professores entrevistados.

O questionário foi utilizado com o objetivo de identificar os docentes que utilizam a pesquisa no desenvolvimento do trabalho acadêmico e obter algumas informações gerais sobre eles. Responderam o questionário 15 professores. Destes professores selecionamos 9 para serem entrevistados. A escolha desses sujeitos aconteceu por estarem envolvidos com disciplinas nas quais constam indicativos de trabalho com a pesquisa no título, na ementa ou nos programas de ensino.

Participaram do trabalho de grupo focal 14 estudantes, cuja composição foi de dois grupos com sete estudantes do sétimo período em cada grupo, sendo que um grupo foi formado com estudantes do período matutino e o outro com estudantes do vespertino. Esses sujeitos foram escolhidos por estarem cursando o penúltimo período do curso. Inicialmente nosso objetivo seria realizar a pesquisa com estudantes do último período, ou seja, oitavo período. Mas pelo fato da entrada das turmas ser anual, no momento que realizamos a pesquisa o período mais adiantado na dinâmica curricular foi o sétimo.

Para diferenciar as falas dos grupos, usaremos a abreviação (GFM) para o grupo focal composto por estudantes do $7^{\circ}$ período matutino e (GFV) para o grupo focal composto por estudantes do $7^{\circ}$ período vespertino. Já a análise dos dados acorreu nos seguintes momentos: a) organização dos dados levantados com elaboração de 
uma síntese com as evidências da pesquisa; b) elaboração de categorias de análise; c) confronto dos dados das diferentes fontes e sujeitos com a literatura.

\section{A pesquisa nas Politicas Curriculares}

No ano de 2001 são constituídas as novas políticas curriculares para formação docente no Brasil. Sob orientação da Lei de Diretrizes e Bases da Educação Nacional, Lei no 9394/96, o Parecer CNE/CP $\mathrm{n}^{\circ}$ 09, de 8 de maio de 2001 e a Resolução CNE/CP n ${ }^{\circ} 01$, de 18 de fevereiro de 2002 estabeleceram as Diretrizes Curriculares Nacionais para os cursos de Formação Inicial de professores para Educação Básica, inclusive para as licenciaturas, como a Educação Física, apresentando princípios orientadores gerais para sua organização e estruturação.

A pesquisa foi incluída no Parecer CNE/CP n 09/2001 como um dos princípios norteadores para o preparo e o exercício profissional: "[...] a pesquisa com foco no processo de ensino e de aprendizagem, uma vez que ensinar requer tanto dispor de conhecimento e mobilizá-lo para a ação, como compreender o processo de construção do conhecimento" (BRASIL, 2001, p. 2).

Apesar de a pesquisa ser considerada como uma importante atividade na formação e no exercício profissional dos professores, $\mathrm{o}$ Parecer CNE/CP n 09/2001 não esclarece qual é sua natureza, apenas indicando que deve estar relacionada ao processo de ensinoaprendizagem. Se observarmos o que consta nos Referenciais para Formação de Professores, podemos inferir que a natureza da pesquisa realizada pelo professor da Educação Básica, defendida pelas Diretrizes Curriculares para a formação de professores para a Educação Básica não é científica, ou acadêmica:

E quando investiga, reflete, seleciona, planeja, organiza, integra, avalia, articula experiências, recria e cria formas de intervenção didática junto aos seus alunos, para que eles avancem em suas aprendizagens, que ele produz conhecimento pedagógico. Assim, a investigação que o professor 
realiza se diferencia da pesquisa acadêmica pela sua natureza e intencionalidade: quando se toma a prática, em toda a sua complexidade, como objeto para a reflexão, constitui-se um campo de conhecimento que é específico do professor. (BRASIL, 1999, p. 108).

Nota-se que, segundo os Referenciais, a pesquisa realizada pelo professor da Educação Básica é diferenciada da pesquisa acadêmica (científica), o que pode configurar como um descomprometimento da produção realizada pelos professores na Educação Básica com a pesquisa científica ou acadêmica. É importante ressaltar que os Referenciais para a Formação de professores foi um documento publicado em 1999 que serviu como orientações oficiais sobre os ajustes curriculares dos cursos de formação de professores no Brasil que aconteceram com as Diretrizes Curriculares Nacionais para os cursos de Formação Inicial de professores para Educação Básica (FREITAS, 2002).

\section{A PESQUISAE A ORGANIZAÇÃo CURRICULAR DO CURSO DE LICENCIATU-} RA

A formação docente, conforme, Borges (1998), Guimarães (2006), Imbernón (2006, 2009), Molina Neto (1997), Nóvoa (2000), Tardif (2002) e Veiga (2009) é um processo contínuo. Neste processo, o que se denomina Formação Inicial muitas vezes não se constitui como o primeiro momento formativo dos professores. As várias experiências vividas pelo professor ao longo de sua vida, assim como suas experiências pré-profissionais, quando ocorrem, se constituem como momentos formativos significativos para o professorado (BORGES, 1998; TARDIF, 2002).

Entretanto, a Formação Inicial possui uma importância singular na constituição de um professor. Para Imbernón (2006), é na formação inicial que o futuro professor (re)elabora o arquétipo de sua profissão, de modo que os valores e as crenças sobre a educação passarão a ter novos significados mediante seu processo de aprendizagem. 
No Brasil, a Formação Inicial acontece em instituições de ensino superior, nas quais professores em formação, por meio de um currículo que estabelece uma sequência de experiências de aprendizagem, adquirem ou melhoram seus conhecimentos, o que lhes permite intervir no ensino (GARCIA, 1999). A Formação Inicial cumpre assim três funções básicas: primeiro, realiza a preparação dos futuros professores para o trabalho docente; segundo, confere a licença para o exercício do magistério; e, por fim, cumpre função dúbia de agente de mudança, contribuindo na transformação da educação e na socialização da cultura dominante (GARCIA, 1999).

Como já foi dito anteriormente, as orientações para a formulação dos currículos dos cursos de Formação Inicial de professores são obtidas a partir das políticas curriculares. Entretanto, os sujeitos que modelam essas orientações nas instituições de ensino não são passivos dessas políticas. Segundo Gimeno Sacristán (2000), os professores podem agir de pelo menos três diferentes maneiras, a saber: a) reproduzir os currículos das políticas curriculares oficiais; b) realizar práticas mais aperfeiçoadas através das condições objetivas postas na cultura escolar, e; c) buscar novos caminhos para a superação das políticas curriculares. Sendo assim, segundo o seu projeto pedagógico, a Instituição Formadora optou em superar as políticas curriculares estabelecendo, em seu Projeto Político Pedagógico, uma concepção de pesquisa como um meio de produção de conhecimento e posta como princípio nuclear do curso em uma relação indissociável com o ensino e a extensão em todas as disciplinas.

De uma forma geral, todos os professores entrevistados reconheceram a pesquisa como importante elemento no Projeto Pedagógico da Instituição Formadora. No entanto, apenas três, dos nove professores, compreenderam que a pesquisa deve ser tratada como um elemento integrado ao ensino e à extensão em todas as disciplinas. 
Os discentes fazem um balanço positivo da inclusão da pesquisa no currículo da Instituição Formadora ao afirmarem sua presença no currículo: "[...] A pesquisa tem sido trabalhada em diversas disciplinas ao longo do nosso currículo [...]" (GFV).

Como a indicação de inclusão da pesquisa no currículo do curso analisado aponta para que a pesquisa seja posta como principio nuclear, é relevante analisar se o tipo de organização curricular contribui para esse tipo de inclusão da pesquisa.

Nessa análise, utilizamos os estudos realizados por Bernstein (1988). Segundo este autor, o currículo pode ser concebido conceitualmente de dois modos: integrado ou coleção. O currículo de tipo integrado não possui nítidos limiares entre os conhecimentos, possuindo, dessa forma, uma relação aberta, flexível entre eles. Já o currículo do tipo coleção é rígido e possui uma relação fechada entre seus conhecimentos, que são delimitados e isolados.

O currículo prescrito da Instituição Formadora no Projeto Político Pedagógico aproxima-se do currículo tipo coleção, pois os limiares entre as disciplinas estão bem delimitados. Isto ocorre porque a aproximação entre as diferentes disciplinas está condicionada a uma aproximação entre os docentes, requerendo um trabalho coletivo bem articulado (TORRES SANTOMÉ, 1998), o que não parece haver na Instituição Formadora. De acordo com alguns docentes que participaram da pesquisa, o único momento que acontece o planejamento coletivo com a participação de todos os professores é a semana pedagógica, que, segundo um professor, não tem sido suficiente para tratar de questões relacionadas à organização do trabalho pedagógico:

[...] para organizar esse currículo, uma semana pedagógica não é suficiente, nem para apontar os problemas, muito mais para resolvê-los. [...] A semana pedagógica seria um espaço para se pensar o currículo. [...] A semana pedagógica não consegue discutir questões relacionadas à pesquisa no projeto político pedagógico. Ela acaba sendo preenchida com questões organizacionais [...] (Professor 3). 
O professor 3 expõe o problema relacionado à organização do trabalho pedagógico no contexto coletivo dos professores, influenciando inevitavelmente na ação do currículo. Sem haver momentos de planejamento em conjunto, a tendência é que os professores realizem o trabalho no contexto da aula de forma isolada.

Tendo como referência a teoria curricular de Bernstein (1988), inferimos também que, nesta organização, o currículo prescrito no Projeto Político Pedagógico apresenta características de um currículo do tipo coleção e com uma forte classificação, o que pode comprometer sobremaneira a inclusão da pesquisa como um dos princípios do currículo.

André (2001, p. 61) considera que, para se ter a pesquisa como eixo ou núcleo do curso, integrando o projeto de formação da instituição, como é o caso da Instituição Formadora, a organização curricular deve estar estrategicamente articulada, de forma coletiva, em todo o processo formativo, com o objetivo de "[...] desenvolver habilidades e atitudes de investigação nos futuros professores", seja no interior das disciplinas ou nas várias atividades acadêmicas.

Para se ter a pesquisa como principio curricular, segundo Fontana (2006), é necessário que a instituição proporcione momentos de planejamentos coletivos, interdisciplinares, com o propósito de se compreender os fenômenos educacionais e a sua problematização, bem como desenvolver atitudes investigativas. Para Almeida (2008), a fim de se formular um programa sustentado na metodologia investigativa, em que exige um envolvimento dos professores de forma coletiva, é necessário o compromisso institucional e o engajamento desses professores.

Assim, em um curso de formação docente que vislumbre a formação do professor, no qual a pesquisa é considerada como princípio nuclear, é importante que sua organização curricular supere a lógica fragmentada que configura o currículo do tipo coleção. 


\section{A INCLUSÃO DA PESQUISA NAS DISCIPLINAS}

Embora no currículo analisado exista uma indicação de que a pesquisa deva estar presente em todas as disciplinas do currículo, constatamos que algumas disciplinas possuem uma indicação mais específica de inclusão da pesquisa. O tempo reservado para estas disciplinas é de $1160 \mathrm{hs}$, o que representa um total de mais de 35,6\% das horas do curso. Essas indicações estão em seus títulos, ementas ou respectivos programas. São elas: a) Oficina Experimental, b) Introdução ao Pensamento Científico, c) Núcleos Temáticos de Pesquisa, d) Disciplinas que abordam conhecimentos específicos da Educação Física, e e) Estágio Supervisionado. Essas disciplinas atuam na formação pela e para a pesquisa, ou seja, objetivam instrumentalizar os estudantes para desenvolverem atividades de investigação e trabalham no sentido de articular a pesquisa juntamente com o processo de ensino.

A Oficina Experimental é uma disciplina que utiliza a pesquisa como instrumento para investigar problemas oriundos da prática pedagógica em diversos ambientes educacionais em que a Educação Física estabelece intervenção. Seu objetivo é, pois, contribuir para a construção de projetos investigativos que sinalizem ações direcionadas para a superação de problemas da prática pedagógica no campo de atuação.

Pela sua especificidade, essa disciplina aborda os campos não escolares, sendo organizada em um formato no qual os estudantes devem realizar uma pesquisa de campo. Todos os interlocutores da pesquisa reportaram-se a essa disciplina como sendo importante para desenvolver atividades investigativas.

Para os estudantes que participaram do grupo focal, a disciplina foi de grande valia por proporcionar uma experiência com a pesquisa, mas eles consideraram que houveram problemas em seu desenvolvimento, como a falta de conhecimento dos professores sobre como desenvolver a disciplina e a falta de rigor na elaboração das pesquisas dos estudantes. 
A disciplina Introdução ao Pensamento Científico é responsável por abordar conhecimentos filosóficos, epistemológicos e relacionados ao desenvolvimento de pesquisas. Ela possui uma importância singular no currículo da Instituição Formadora, pois é responsável por tratar de conhecimentos fundamentais sobre a Ciência. São abordados conhecimentos de natureza científica a partir de uma prática histórica e dinâmica.

Esta disciplina tem conseguido grande aprovação entre os estudantes, visto que eles consideraram-na importante no currículo da Instituição Formadora, principalmente por abordar as principais matrizes do conhecimento científico: o positivismo, a fenomenologia e o materialismo histórico-dialético. Este foi um dos pontos mais abordados no grupo focal quando se tratava da disciplina em questão, o que pode ser constatado no trecho destacado:

A Introdução ao Pensamento Científico foi uma disciplina que mostrou várias concepções, vários olhares que se pode ter. Foram expostas as formas de pesquisa e o estudante escolhe o pensamento que vai fundamentar sua pesquisa, a forma que vai seguir. Foi válida por isso, pelas concepções abordadas e por possibilitar com que o estudante escolha com autonomia qual concepção utilizar (sic) (GFV).

$\mathrm{Na}$ Instituição Formadora, as disciplinas relacionadas aos conhecimentos específicos da Educação Física são relacionadas com a pesquisa, sendo que a organização dessas disciplinas tem o objetivo, de acordo um professor, de superar a lógica dos currículos com ênfase nas chamadas disciplinas práticas. Esse modelo teve maior ênfase nos currículos dos cursos de formação de professores de Educação Física no final da década de 1970. Nessa organização, as disciplinas ditas práticas eram organizadas para promover a demonstração e a execução de habilidades técnicas, e a ênfase do ensino estava em promover o desenvolvimento do desempenho físicotécnico (BETTI; RANGEL-BETTI, 1996).

$\mathrm{Na}$ proposta da Instituição Formadora, os conhecimentos da ginástica, dos jogos, do esporte, das lutas, da dança, do lazer, das 
linguagens corporais expressivas e culturais, do movimento corporal, entre outros, são conteúdos históricos matriciais do campo acadêmico e do campo de intervenção profissional da Educação Física, importantes em um curso de formação de professores. Essas disciplinas abordam, pois, os métodos de ensino e os conhecimentos relacionados à pesquisa.

Dois professores identificaram que a carga horária dessas disciplinas é pequena, o que acaba dificultando o trabalho de inclusão da pesquisa. Vejamos um exemplo: "Eu considero muito pequena a carga horária da disciplina, e acabamos aligeirando algumas discussões; lançamos mão de atividades extra-curriculares, para evitar a perda [...] (Professor 2).

Já os estudantes consideraram positiva a organização dessas disciplinas devido ao seu enfoque ampliado:

[...] o mais importante é a ampliação. É saber que o objetivo dessas disciplinas, principalmente as esportivas, não é somente ensinar técnicas para o aluno. Então, a pesquisa nessas disciplinas é fundamental para ampliar o que é a disciplina, e como ela se comporta na escola (GFM).

Consideramos que a inclusão da pesquisa nas disciplinas relacionadas às práticas corporais representa considerável avanço, pois estabelecem um enfoque mais amplo em sua abordagem. No entanto, ainda parece ser um desafio a organização e sistematização dos conhecimentos que deverão ser tratados nestas disciplinas neste novo enfoque.

Os Núcleos Temáticos de Pesquisa fazem parte de um componente curricular que tem o objetivo de contribuir com a elaboração dos Trabalhos de Conclusão de Curso, relatórios de pesquisas realizadas pelos estudantes apresentados no final da disciplina em uma defesa pública perante uma banca examinadora. Em um curso de licenciatura, os Trabalhos de Conclusão de Curso possuem uma grande importância na formação dos estudantes, por permitir um olhar mais próximo da realidade a partir de um trabalho de investigação com uma maior profundidade teórica e metodológica. 
A construção do Trabalho de Conclusão de Curso pode constituir-se como um momento significativo de produção de conhecimento sobre o trabalho docente se for bem articulada no processo de Formação Inicial (ALMEIDA, 2008).

É importante, nesse processo, que a realidade do trabalho docente seja problematizada para ajudar os estudantes na compreensão dessa realidade podendo também muni-los de possibilidades de enfrentá-la.

Como o Projeto Pedagógico do curso de licenciatura da Instituição Formadora prevê uma perspectiva ampliada de docência, os núcleos temáticos para a construção dos Trabalhos de Conclusão de Curso possuem um enfoque em quatro temas diferentes e relacionados com alguns campos de intervenção do professor de Educação Física. Os núcleos temáticos são: a) Educação Física e Escola; b) Saúde e Educação; c) Lazer e Educação; d) Educação Física e Esporte.

O Estágio Supervisionado possui a pesquisa incluída como eixo central, e tem como propósito, segundo seu programa de ensino, identificar e compreender a organização do trabalho pedagógico escolar e da Educação Física na escola, propiciando a intervenção investigativa, relacionando-a com possibilidades de novas formas de ação.

Para os estudantes o estágio é um importante espaço de formação para e pela pesquisa e como um importante momento de aproximação com a realidade escolar. O Grupo Focal Vespertino reconheceram no estágio um espaço de inclusão da pesquisa:

[...] A instituição incentiva a pesquisar. A disciplina que mais incentiva é o estágio [...]. As disciplinas conseguem instigar os alunos a pesquisar, [...]. Uma disciplina é o Estágio que comecei a perceber a importância da pesquisa. [...] aprendemos a pesquisar de verdade no estágio que é a hora que colocamos tudo em prática o que estudamos (sic) (GFV). 
Os participantes desse grupo focal ressaltaram que são incentivados a pesquisar e a aprender a pesquisar, o que é bastante significativo para esses futuros professores. Já o Grupo Focal Matutino considerou o estágio como um dos momentos mais importantes do currículo no processo de aproximação com a realidade escolar: "Enquanto disciplina, o que a gente mais consegue fazer ligação com escola é nas aulas de estágio, a disciplina que envolve pesquisas de campo dentro da área escolar [...]" (GFM).

Esta perspectiva está de acordo com a posição de Almeida (2008), André (2001, 2006), Pimenta; Lima (2008) e Pimenta (2006), que concebem o estágio como um espaço em que a pesquisa pode ser incluída e que pode possibilitar uma articulação próxima entre a universidade e a escola, em que as práticas pedagógicas podem ser analisadas. É a oportunidade que se tem de realizar o confronto entre as teorias pedagógicas com a realidade escolar. Parece que este tem sido o enfoque dado pela Instituição Formadora no estágio.

\section{Considerações Finals}

Este trabalho teve como objetivo analisar o lugar da pesquisa no currículo de um curso de Formação Inicial de professores de Educação Física. Partimos da ideia de que o currículo de um curso de Formação Inicial de professores é construído em um processo complexo e em determinado contexto sócio-histórico em que diferentes decisões são tomadas, desde as orientações estabelecidas pelas políticas curriculares educacionais até a sala de aula das instituições de ensino (GIMENO SACRISTÁN, 2000). Procuramos, então, num primeiro momento, compreender se a pesquisa é componente integrante das Diretrizes Curriculares Nacionais para formação do professor para a Educação Básica. Também realizamos um trabalho de campo em um curso de licenciatura em Educação Física, em que analisamos a concepção e a indicação de inclusão da pesquisa estabelecida no projeto político-pedagógico do curso investigado e a percepção dos docentes e discentes sobre a inclusão da pesquisa em seu currículo. 
Desse modo, foi identificado que a pesquisa está incluída no Projeto Pedagógico como um meio de produção de conhecimento, procurando superar as orientações das Diretrizes Curriculares Nacionais para formação de professores para a Educação Básica que concebem a pesquisa realizada pelo professor da Educação Básica diferenciada da pesquisa científica.

No projeto de curso, existe a orientação para que, em todas as disciplinas seja observada a indissociabilidade entre ensino, pesquisa e extensão. No entanto, algumas possuem uma indicação específica de inclusão da pesquisa (Oficina Experimental, Introdução ao Pensamento Científico, Núcleos Temáticos de Pesquisa, Disciplinas que abordam conhecimentos específicos da Educação Física, e Estágio Supervisionado).

Foi identificado que as disciplinas têm proporcionado aos estudantes acesso aos conhecimentos relacionados à pesquisa científica com o objetivo de instrumentalizá-los para desenvolver atividades de investigação e existe a intenção de articular a pesquisa com o processo de ensino. Esse dado foi também percebido pelos interlocutores que ainda compreenderam a pesquisa enquanto um elemento presente no currículo do curso investigado. É importante salientar que os interlocutores apontaram dificuldades que alguns professores apresentaram no processo de inclusão da pesquisa, em algumas disciplinas, principalmente aquelas relacionadas às práticas corporais.

Gostaríamos de ressaltar que a formação de professores com capacidade para realizar pesquisa deva ser um processo contínuo, sem fim, assim como a formação docente. 
Research training in Physical Education teacher
Abstract: This study aims to analyze the place of
research in the curriculum of a course of initial teacher
of Physical Education for Basic Education. Were used
as instruments for data collection to document analysis,
questionnaire, a semi-structured interviews and focus
groups. It was understood that the research has an
indication of inclusion in all disciplines. The speakers
acknowledged the existence of the survey's inclusion
in the curriculum of the degree course in Physical
Education institution. It also emphasized that this
process has limits and possibilities.
Keywords: Faculty. Curriculum. Research. Physical
education

La investigación en la formación inicial de profesores de Educación Física

Resumen: Este estudio pretende analizar el lugar de la investigación en el currículum de un curso de formación inicial del profesorado de Educación Física para la Educación Básica. Se utilizaron como instrumentos para la recolección de datos para el análisis de documentos, cuestionario, entrevistas semi-estructuradas y grupos focales. Se entendía que la investigación tiene una indicación de su inclusión en todas las disciplinas. Los oradores reconocieron la existencia de la inclusión de la encuesta en el currículum de la carrera en la institución de Educación Física. También hizo hincapié en que este proceso tiene sus límites y posibilidades.

Palabras clave: Docentes. Currículum, investigación. Educación física

\section{REFERÊNCIAS}

ALMEIDA. M. I. Ensino com pesquisa na licenciatura como base na formação docente. In: ENDIPE: trajetórias e processos de ensinar e aprender: lugares memórias e culturas. Porto Alegre. Livros. Porto Alegre: EDIPCRS, 2008. CD-ROM.

ANDRÉ. M. Pesquisa, formação e prática docente. In: ANDRÉ, M. (Org.). O papel da pesquisa na formação e na prática dos professores. Campinas: Papirus, 2001. p. $11-25$

ANDRÉ. M. Ensinar a pesquisar: como e para quê. In: VEIGA, I. P. A. Lições de didática. Campinas: Papirus, 2006.

BERNSTEIN, B. Clases, códigos e control: hacia uma teoria de las transmisiones educativas. Madri: Ediciones Akal., 1988. 
BETTI M.; RANGEL-BETTI I. C. R. Novas perspectivas na formação profissional em Educação Física. Revista Motriz, Rio Claro, v. 2, n.01, p.10-15, 1996.

BORGES, C. M. F. O professor de educação física e a construção do saber. Campinas: Papirus, 1998.

BRACHT, V. Educação Física \& Ciência: cenas de um casamento (in)feliz. 2. ed. ljuí: Ed. Unijuí, 2003.

BRASIL. Referenciais para formação de professores. Brasília, DF: Secretaria de Educação Fundamental, 1999.

BRASIL. Conselho Nacional de Educação. Parecer no. 09. Institui as Diretrizes Curriculares Nacionais para a Formação de Professores da Educação Básica, em Nível Superior, Curso de Licenciatura, de Graduação Plena. Brasília, 08 de maio de 2001.

BRASIL. Conselho Nacional de Educação. Resolução no 01: Institui as Diretrizes Curriculares Nacionais para a Formação de Professores da Educação Básica, em nível superior, curso de licenciatura, de graduação plena. Brasília, 18 de fevereiro de 2002.

BRASIL. Conselho Nacional de Educação. Resolução no 02: Institui a duração e a carga horária dos cursos de licenciatura, de graduação plena, de formação de professores da Educação Básica em nível superior. Brasília, 19 de fevereiro de 2002.

FONTANA. M. I. A prática de pesquisa: relação teoria e prática no curso de pedagogia. 2006. Dissertação (Mestrado em Educação), Pontifícia Universidade Católica, Paraná, Curitiba, 2006.

FREITAS, H. C. L. de. Formação de professores no Brasil: 10 anos de embate entre projetos de formação. Educação \& Sociedade, Campinas, v. 23, n. 80, p. 136167, 2002.

GARCIA, C. M. Formação de professores: para uma mudança educativa. Portugal: Editora Porto,1999.

GIMENO SACRISTÁN, J. O currículo: uma reflexão sobre a prática. 3.ed. Porto Alegre: Artmed, 2000.

GUIMARÃES, V. S. Formação de professores: saberes, identidade e profissão. 3.ed. Campinas: Papirus, 2006.

IMBERNÓN, F. Formação docente e profissional: forma-se para a mudança e a incerteza. 6.ed. São Paulo: Cortez, 2006.

IMBERNÓN, F.. Formação permanente do professorado: novas tendências. São Paulo: Cortez, 2009. 
MOLINA NETO, V. M. Formação profissional em Educação física e Esportes. In: CONBRACE, 10, 1997, Goiânia. Anais. Goiânia: Potência, 1997. v. 1.

NÓVOA, A. Os professores e sua história de vida In: NÓVOA. (Org). Vida de professores. 2. ed. Porto: Editora Porto, 2000.

PÉREZ GÓMEZ, A. O pensamento prático do professor: A formação do professor com profissional reflexivo. In: NÓVOA, A. (Org.). Os professores e a sua formação. Lisboa: Dom Quixote, 1992.

PIMENTA, S.G. Professor reflexivo: construindo uma crítica. In: PIMENTA, S.G. e GHEDIN, E. (Orgs.). Professor reflexivo no Brasil: gênese e crítica de um conceito. 4. ed. São Paulo: Cortez, 2006.

PIMENTA, S.G.; LIMA, M. S. L. Estágio e Docência. 3.ed. São Paulo: Cortez, 2008.

TAFFAREL, C. N. Z. A formação do profissional da educação: o processo de trabalho pedagógico e o trato com o conhecimento no curso de educação física. 1993. Tese (Doutorado em Educação), Faculdade de Educação, Universidade Estadual de Campinas, Campinas, 1993.

TARDIF, M. Saberes docentes e formação profissional. Petrópolis: Vozes: 2002.

TORRES SANTOMÉ, J. Globalização e interdisciplinaridade: o currículo integrado. Porto Alegre: Artes Médicas, 1998.

VEIGA, I. P. A. A aventura de formar professores. Campinas: Papirus, 2009.

Auxílio: CAPES/Reuni

Endereço para correspondência:

Rua: R- 29, Qd.: 29, Lt.: 08. Conjunto Itatiaia II,

Goiânia GO, Brasil,

CEP: $74690-540$

Recebido em: 24.10.2011

Aprovado em: 26.04.2012

Movimento, Porto Alegre, v. 18, n. 02, p. 169-186, abr/jun de 2012. 
